\title{
Innovative Use of Light-Weight Radioisotopes in Therapeutics and the Engineering of Light-Power Generators
}

\author{
Alfred Bennun \\ Biological Sciences-Newark Campus, Rutgers, The State University of New Jersey, Newark, USA \\ Email: alfr9@hotmail.com
}

Received November 16, 2012; revised December 18, 2012; accepted December 27, 2012

\begin{abstract}
Light weight radioisotope (LWR) ${ }^{89} \mathrm{Sr}$ and ${ }^{90} \mathrm{Sr}$ could be obtained from used rods in fission atomic plants. The economics of the disposal of nuclear bars indicate the convenience to develop added value applications. The difference in $\mathrm{t}_{1 / 2}$ allows ${ }^{89} \mathrm{Sr}$ to deliver its energy at a rate 200 times higher than ${ }^{90} \mathrm{Sr}$. A large emission number of low penetrating power particles in a short time characterize ${ }^{89} \mathrm{Sr}$, which allows that these highly radioactive LWR involves a rather limited danger. Chemical similitude of calcium and strontium uptake has led to the use of ${ }^{89} \mathrm{Sr}$ in treatment of bone cancer metastasis. ${ }^{89} \mathrm{Sr}$ damages animal tissues because ionize water, but penetrates through the skin about: 5 to $8 \mathrm{~mm}$. Hence, to obtain it in insoluble form, like obtaining ${ }^{89} \mathrm{Sr}$ silicate, could make possible its wider use. Purifying ${ }^{89} \mathrm{Sr}$ from contaminant ${ }^{90} \mathrm{Sr}$ allows that after one year do not leave any contamination. LWR could be covered with scintillators substances, which by subtracting kinetic energy from beta-radiation, emit light and function as a major source of shielding. This treatment engineers Radioisotope Light Generators (RLG). Their light could activate photovoltaic cells (PV), which could lead to nano-devices without moving parts RLG-PV.
\end{abstract}

Keywords: $\beta$-Emission; Scintillation Crystals; Strontium-89/90; Photovoltaic Cells; RLG; Radioisotope Therapseutic

\section{Introduction}

Fission of ${ }^{235} \mathrm{U}$ after its interaction with a neutron produces various fission fragments, including ${ }^{90} \mathrm{Sr}$ and ${ }^{89} \mathrm{Sr}$ but not at the same time. ${ }^{89} \mathrm{Sr}$ is produced at slightly less quantities with a higher activity ratio of about 166/1 than ${ }^{90} \mathrm{Sr}$.

${ }^{89} \mathrm{Sr}$ and ${ }^{90} \mathrm{Sr}$ half-life differences and their yielding energy allow fitting specific designs for a large range of devices [1].

${ }^{90} \mathrm{Sr}^{38}\left(\mathrm{t}_{1 / 2}=28.8\right.$ years $) \rightarrow{ }^{90} \mathrm{Y}^{39}+\beta(2.28 \mathrm{MeV})+\bar{v}$

${ }^{90} \mathrm{Y}^{39}\left(\mathrm{t}_{1 / 2}=64 \mathrm{~h}\right) \rightarrow{ }^{90} \mathrm{Zr}^{40}+\beta(0.68 \mathrm{MeV})+\bar{v}$

${ }^{89} \mathrm{Sr}^{38}\left(\mathrm{t}_{1 / 2}=50.55\right.$ days $) \rightarrow{ }^{90} \mathrm{Y}^{39}+\beta(1.5 \mathrm{MeV})+\bar{v}$.

The difference in $\mathrm{t}_{1 / 2}$ allows ${ }^{89} \mathrm{Sr} \beta$-emission $(2.82 \times$ $\left.10^{4} \mathrm{Ci} / \mathrm{g}\right)$ at a rate 210 times higher than of ${ }^{90} \mathrm{Sr}(138 \mathrm{Ci} / \mathrm{g})$ [2]. If the cost to separate these radioisotopes from each other is avoided, they could be initially used based mainly in the activity of ${ }^{89} \mathrm{Sr}$. Latter on the ${ }^{89} \mathrm{Sr}$ decay of $99 \%$ in one year allows a left-over of $1 \%$ of near uncontaminated ${ }^{90} \mathrm{Sr}$, which could be useful for applications requiring much longer periods of time.

\section{LWR in Therapeutics}

The difference in $\mathrm{t}_{1 / 2}$ allows that ${ }^{89} \mathrm{Sr}$ a rate of $\beta$-emission
200 times higher than ${ }^{90} \mathrm{Sr}$. $\beta$-radiation from ${ }^{89} \mathrm{Sr}$ damages animal tissues because ionize water, but penetrates through the skin about: 5 to $8 \mathrm{~mm}$ [3]. Thus, allowing manipulation of small amounts of ${ }^{89} \mathrm{Sr}$ with gloves, glasses and thick laboratory clothing. In solution ${ }^{89} \mathrm{Sr}$ has been administered as a palliative of pain of metastatic prostate cancer in doses of $150 \mathrm{MBq}$. Its bone-seeking properties favored its use at higher doses, in the treatment of bone cancer metastasis.

Radioactive ${ }^{89} \mathrm{Sr}$ and ${ }^{90} \mathrm{Sr}$ are extremely dangerous, because when ingested replaces $\mathrm{Ca}^{2+}$ in their physiological functions.

However, in an insoluble form like ${ }^{89} \mathrm{Sr}$ silicate, a solid, could be used in the form of near microscopic implants, that inserted in quantities related to the tumors size could have a slow but persistent effect on reducing the extend of metastasis [4].

$\beta$-particle energy dissipates through the $5 \mathrm{eV}$ stopping power per molecule of water. Since, $460 \mathrm{KJ} / \mathrm{mol}$ is the average energy of ionization, the mean energy of $1 \mathrm{MeV}$ per each $\beta$-particle emitted by ${ }^{89} \mathrm{Sr}$, allows a theoretical maximal ionization: $1.8 \times 10^{5}$ molecules of water. Hence, $1 \mathrm{nmol}$ of pure ${ }^{89} \mathrm{Sr}$ (89 ng equivalent to $95 \mathrm{MBq}$ ) emits over 50 days $4 \times 10^{14} \mathrm{MeV} \beta$-particles, which multiply 
by $1.8 \times 10^{5}=7 \times 10^{19}$ ionized water molecules or $1.2 \times$ $10^{-1} \mathrm{mg}$ of $\mathrm{H}_{2} \mathrm{O}$ or $\mathrm{ml}$. This number corresponds to the size of a small tumor, but the radiation characteristics of the radioisotope allow the use of a large number of ${ }^{89} \mathrm{Sr}$ nano-implants for in-situ metastasis treatments.

${ }^{89} \mathrm{Sr}$ activity of $2.82 \times 10^{4} \mathrm{Ci} / \mathrm{g}$ is not much smaller than radium $5 \times 10^{4} \mathrm{Ci} / \mathrm{g}$. A large emission number of low penetrating power particles in a short time characterize ${ }^{89} \mathrm{Sr}$, which allows the use highly radioactive involving a rather limited danger.

The half-life of ${ }^{89} \mathrm{Sr}$ may restrict its use, but it could be turned into a radioisotope of choice, because in less than 1 year its initial radioactivity became reduced to less than $1 \%$, facilitating its disposal.

\section{Innovative Radioisotope Light Generators}

The medical market is rather small for the overall quantities of ${ }^{89} \mathrm{Sr}$ generated at nuclear facilities. However, if used as an alternative form of energy, its advantage could be a possible low prize which may be an incentive for the development of a consumption market.

Light weight radioisotope (LWR) could be used in innovative ways at scales much smaller than those of nuclear reactors. LWR could be engineered by contact the scintillator as a single chip, without moving parts: Radioisotope Light Generators (RLG). This one functions as a lamp which could be couple to a photovoltaic (PV) system to generate electricity RLG-PV. It is emphasized that these energy transducer devices play the role of long-lasting batteries.

\section{Shielding Requirements According to $\beta$ Energy}

If a given scintillation thickness, does not totally eliminate the kinetic energy of the particles, and for example from 1 $\mathrm{MeV}$ retains only $0.01 \mathrm{MeV}$, its remaining effects would correspond to the decreased energy level shown on Table 1.

Table 1. $\beta$-reaching distance: The energy of beta decreases by exciting atoms, ionizing molecules and electron slowing-down (bremsstrahlung), which may generate $x$-rays. The effect of $x$-rays or $\gamma$ is to transfer energy to electrons with photoelectric effects ionizing molecules and Compton interaction $[3,5]$.

\begin{tabular}{cccc}
\hline Energy of $\beta[\mathrm{MeV}]$ & Air $[\mathrm{m}]$ & Corporal tissue $(\mathrm{cm})$ & Aluminum $[\mathrm{mm}]$ \\
\hline 0.01 & 0.023 & 0.00027 & - \\
0.5 & 1.5 & 0.18 & 0.59 \\
1 & 4.2 & 0.5 & 1.5 \\
1.5 & 6.7 & 0.8 & 2.4 \\
3 & 12.6 & 1.5 & 5.6 \\
\hline
\end{tabular}

${ }^{89} \mathrm{Sr}$ decays by beta emission with a peak equal to 1.5 $\mathrm{MeV}$ and a mean of $1 \mathrm{MeV}$ which permit only to penetrate animal tissue by about $0.8 \mathrm{~cm}$ reducing shielding requirements to about $1 \mathrm{~cm}$ of shielding scintillator crystal or glass.

${ }^{89} \mathrm{Sr}$ could be characterized as capable of a potent large emission number of low penetrating power. Hence, allowing protection by establishing a security distance for personal with adequate clotting. For large quantities, it could be used additional covering of unbreakable glass, a shield transparent to light emission. Storage for small amounts requires containers made of glass or aluminum, and depending of quantity cooling conditions.

\section{Selection of Scintillator Shielding and Photon Emission Ranges}

The scintillator-crystals [6-10] act as a shield by absorbing the kinetic energy of $\beta$-particles to reach an excited quantum state and return to its initial state through photon emission.

The scintillator POPOP, which can be used solid or liquid as secondary photon emission $(\lambda)$, also extends $\lambda$-emission to $410 \mathrm{~nm}$ in the violet of the visible spectrum (Table 2). Crystals with added $\mathrm{Al}_{2} \mathrm{O}_{3}$ optimize light transmission and give a red shift of the emission spectrum. The omission of water in the engineering of the RLG crystals may decrease efficiency losses.

Thallium is very expensive, but a $\mathrm{NaI}$ crystal by addition of $\mathrm{Tl}$ in $1 \%$ - $2 \%$ range increases by much the efficiency (Figure 1). Addition of the scintillation substances listed as dimethyl POPOP, etc., could increase efficiency. High light production but is hydroscopic and may be convenient a covering of glass because is susceptible to humidity.

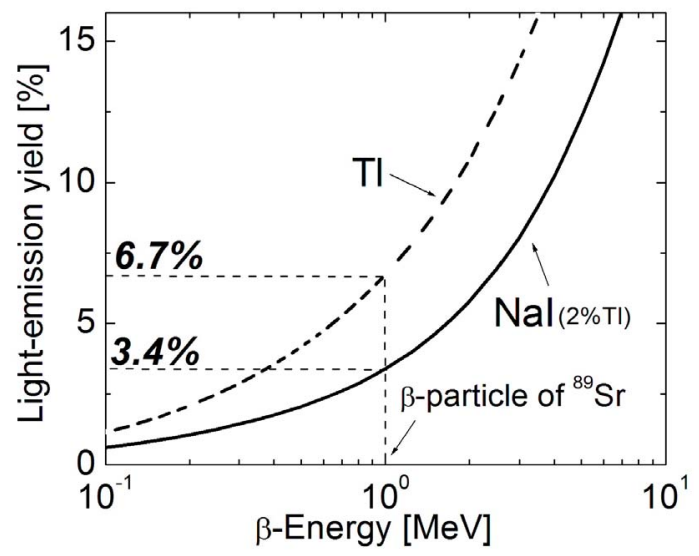

Figure 1. Comparative efficiency of scintillator $(\eta)$ vs. $\beta$ energy $(\mathrm{MeV})$. Radioisotope light generators (RLG) are based in the scintillator stopping power capable of exciting an orbital with photon emission. NaI $\left(3.675 \mathrm{~g} / \mathrm{cm}^{3}\right)$, mean excitation energy: $458.0 \mathrm{eV}, 2 \% \mathrm{Tl}+\beta[1 \mathrm{MeV}] \rightarrow \mathrm{h} v$ (u.v.), $\eta=3.4 \%$. [11]. 
Table 2. Scintillation substances and range of fluorescence emission.

\begin{tabular}{ccc}
\hline Acronym & Scintillation function & Fluorescence emission maximum [nm] \\
\hline Naphthalene & Primary & 322 \\
BBOT & Primary \& Secondary & $425-435$ \\
Butyl-PBD & Primary & $360-365$ \\
PBD & Primary & $360-370$ \\
PPO & Primary & $360-365$ \\
p-Terphenyl & Primary & 340 \\
Bis-MSB & Secondary & $420-430$ \\
Dimethyl POPOP & Secondary & $425-430$ \\
TPB & Secondary & 455 \\
BBQ & Secondary & 477 \\
PbWO & Secondary & $486-510$ \\
\hline
\end{tabular}

Nogues [12] developed a fast, Radiation-Hard Scintillating silica glass through a sol-gel method, by doping organic materials in glass to prepare the scintillating glass. It is possible to dope organic scintillating materials into bulk inorganic glass used as matrix of low-melting lead-tin-fluorophosphates glass [13-16].

\section{RLG Coupling with Photovoltaic Cells}

The scintillator $\mathrm{PbWO}_{4}$ stimulated by electricity rather than by $\beta$-particles has been used to manufacture electrically swtched light bulbes $[9,17]$. Autoscintillator of crystals ${ }^{89} \mathrm{Sr}-\mathrm{WO}_{4}$ with dopants could be used to power electricity independent portable photovoltaic cells.

Figure 2 indicates the convenience of using a scintillator mixture to obtain a better response for the $\beta$ emitted at lower energy, dotting of the crystal like that with $\mathrm{BaF}_{2}: \mathrm{PbWO}_{4}$ to increase maximal transmittance [18].

RLG Nano-crystals, by size engineering, could be made to emit light at different $\lambda$ of the visible spectrum, corresponding acording to increasing their size, to violet, blue, green, orange, etc.

Efficiency of photovoltaic cell (PV) has been highly improved and basically radioisotope light generator RLGlamp coupled to a PV system could be used to generate electricity: RLG-PV, and recharge batteries.

\section{Comparative Advantages of Heat Transfer vs. Light Transfer of Electric Energy}

Table 3 shows that RLG may produce same amount of heat which is easily dissipated by a cooling system, whereas RTG requires heat accumulation to integrate a thermic potential, which turns instable and easily heat-deform RTG devices.

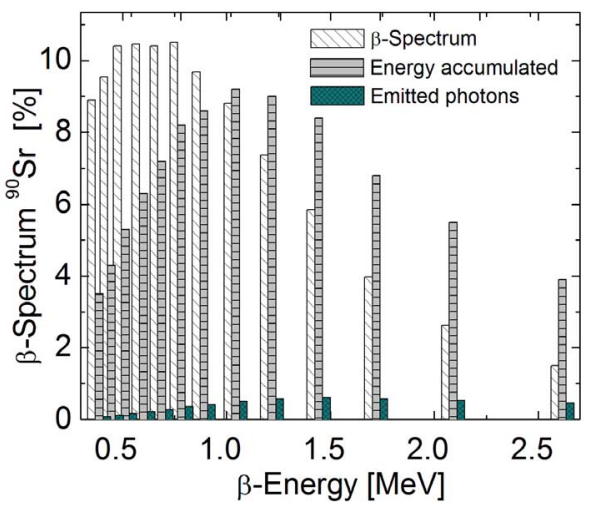

Figure 2. $\beta$-Energy distribution. Calculated as a percentege of the value obtained by summing-up the energy of $\beta$-particles in the range between $0.39 \mathrm{MeV}$ and $2.6 \mathrm{MeV}(\square)$ ). The percentage of $\beta$-particles with less than $0.6 \mathrm{MeV}$ constitute $40 \%$ of the total, but sum up to less than $20 \%$ of total energy. The particles emitted at higher than $0.6 \mathrm{MeV}$, constitute $60 \%$ with $80 \%$ of total energy emitted at an average $1.4 \mathrm{MeV}(\rightleftharpoons)$. The scintillator range efficiency approachs 7\% for $\mathrm{PbWO}_{4}$ ( $)$.

\section{Discussion}

A light-transfer technology could be achieved by using the energy generated by a shielding/covering of the radioisotope with scintillator crystal. It is evaluated the feasibility to develop nuclear electric power sources, small reactors or batteries, operated by light-weight radioisotopes with a scintillation shielding (RLG). Advantages of light emitting systems could be easily transported and deployed and focalized. The engineering simplicity of RLG chips compares favorably with that of Radioisotope Thermo Generators (RTG) (Table 3). A technic for nano-sizing the RLG-crystal, whose engineering is based in contact, allows to crush a crystal to yield a powder. Thus, each individual speck continues to 
Table 3. Comparative yield efficiency of RTG vs. RLG-PV. The ex-Soviet Union constructed lighthouses to illuminate routes in the arctic region.

\begin{tabular}{|c|c|c|c|c|c|c|}
\hline Projects & Radioisotopes & Potency Max (W) & & Electric (W) & Mass $(\mathrm{Kg})$ & Shield (Kg) \\
\hline \multirow{3}{*}{ Beta-M Soviet [**] RTG } & \multirow{3}{*}{${ }^{90} \mathrm{Sr} \rightarrow{ }^{90} \mathrm{Y}+\beta+\bar{v}$} & \multirow{3}{*}{484.5} & Heat & Thermo-Electric & & \\
\hline & & & 230 & $10[*]$ & 0.26 & 560 \\
\hline & & & Scintillation (W) & Photo-Voltaic $30 \%$ & & \\
\hline \multirow[t]{2}{*}{ RLG-PV } & ${ }^{90} \mathrm{Sr} \rightarrow{ }^{90} \mathrm{Y}+\beta+\bar{v}$ & 484.5 & 42.6 & 12.8 & 0.26 & {$[* * *]$} \\
\hline & ${ }^{89} \mathrm{Sr} \rightarrow{ }^{89} \mathrm{Y}+\beta+\bar{v}$ & 44,695 & 2414 & 724 & 0.26 & {$[* * *]$} \\
\hline
\end{tabular}

$\left[{ }^{*}{ }^{90} \mathrm{Sr}\right.$ was in a RTG (Beta-M) yielded $10 \mathrm{~W}$, enough to power a $60 \mathrm{~W}$ compact fluorescent light bulb. The same core of $0.26 \mathrm{~kg}$ but of ${ }^{89} \mathrm{Sr}$ on a RLG battery generates the equivalent of $724 \mathrm{~W}$. Direct light output of ${ }^{89} \mathrm{Sr}$ in RLG could exceed by much a not yet designed ${ }^{89} \mathrm{Sr}-\mathrm{RTG}$ (Beta-M) because it would have the additional conversion steps of thermic to electric and electric to light. [**] Discharged ${ }^{90} \mathrm{Sr}$ from thermoelectric generations are a major source of contamination in the URSS, ${ }^{89} \mathrm{Sr}$ after 4 months delivers only $25 \%$ of initial energy output, but reduce in one year to $1 \%$ the final contamination. [***] Shield RLG-PV many times lighter than RTG.

operate as a RLG capable to couple with very small PV systems.

\section{Conclusions}

The use of the radioisotope in Biological and Medical Science is extensive [19]. In-situ radiation treatments for replacing the therapeutic-radium on the treatment for prostate shrinking, skin cancer, etc., has involved the evaluation of the usefulness of many radioisotopes and as described ${ }^{223} \mathrm{Ra}$ can be replaced by ${ }^{89} \mathrm{Sr}$.

LWR do not generate a chain reaction could be engineered to interact by contact with scintillation substances, as a long time lasting energy source. Shielding without any other protection covering, could be achieved by absorbing the stopping power of the scintillator.

The stopping power of scintillators converts the kinetic energy of beta-particles into light and the decelerated particles into harmless electrons, which could not pollute the environment.

The radio-nucleotide generated light allows developing a lamp RLG that could not be turned off, but it could be displaced to direct the incidence of this scintillation light to photovoltaic cells.

Moreover, optical fibers are available for light conducting systems. The electricity generated in situ like a battery could operate electrical motors which do not need fuel for at least the half-life of the radioisotopes selected.

\section{REFERENCES}

[1] National Nuclear Data Center, "NuDat 2.1 Database," Brookhaven National Laboratory, New York, 2005.

[2] K. Krane, "Introductory Nuclear Physics," 3rd Edition, John Wiley \& Sons, Hoboken, 1987.

[3] M. F. L'Annunziata, "Handbook of Radioactivity Analysis," Academic Press, San Diego, 2003.

[4] S. L. Turner, S. Gruenewald, N. Spry, V. Gebski and on Behalf of the Metastron, "Less Pain Does Equal Better
Quality of Life Following Strontium-89 Therapy for Metastatic Prostate Cancer," British Journal of Cancer, Vol. 84, No. 3, 2001, pp. 297-302. doi:10.1054/bjoc. 2000.1610

[5] A. Rytz, "Recommended Energy and Intensity Values of Alpha Particles from Radioactive Decay," Atomic Data and Nuclear Data Tables, Vol. 47, No. 2, 1991, pp. 205239. doi:10.1016/0092-640X(91)90002-L

[6] N. F. Mott and H. S. W. Massey, "The Theory of Atomic Collisions," Clarendon, Oxford, 1933.

[7] G. F. Knoll, "Radiation Detection and Measurement," John Wiley \& Sons, Hoboken, 2010.

[8] H. Nakamura, Y. Shirakawa, S. Takahashi and H. Shimizu, "Evidence of Deep-Blue Photon Emission at High Efficiency by Common Plastic," Europhysics Letters, Vol. 95, No. 2, 2011, Article ID: 22001. doi:10.1209/0295-5075/95/22001

[9] C. H. Zheng, C. G. Hu, X. Y. Chen, H. Liu, Y. F. Xiong, J. Xu, B. Y. Wan and L. Y. Huang, "Raspite $\mathrm{PbWO}_{4} \mathrm{Na}-$ nobelts: Synthesis and Properties," CrystEngComm, Vol. 12, No. 10, 2010, pp. 3277-3282. doi: $10.1039 / \mathrm{c} 004327 \mathrm{c}$

[10] S. W. Moser, W. F. Harder, C. R. Hurlbut and M. R. Kusner, "Principles and Practice of Plastic Scintillator Design," Radiation Physics and Chemistry, Vol. 41, No. 1-2, 1993, pp. 31-36. doi:10.1016/0969-806X(93)90039-W.

[11] M. J. Berger, J. S. Coursey, M. A. Zucker and J. Chang, "ESTAR, PSTAR, and ASTAR: Computer Programs for Calculating Stopping-Power and Range Tables for Electrons, Protons, and Helium Ions (Version 1.2.3)," National Institute of Standards and Technology, Gaithersburg, 2005. http://physics.nist.gov/PhysRefData/Star/Text/ESTAR.html

[12] J. L. Nogues, S. Majewski, J. K. Walker, et al., "Fast, Radiation-Hard Scintillating Detector: A Potential Application for Sol-Gel Glass," Journal of the American Ceramic Society, Vol. 71, No. 12, 1988, pp. 1159-1163. doi:10.1111/j.1151-2916.1988.tb05809.x

[13] P. A. Tick, "Water Durable Glasses with Ultra Low Melting Temperature," Physics and Chemistry of Glasses, Vol. 25, No. 6, 1984, pp. 149-154.

[14] W. R. Tompkin, R. W. Boyd, D. W. Hall and P. A. Tick, 
"Nonlinear-Optical Properties of Lead-Tin Fluorophospate Glass Containing Acridine Dyes," Journal of the Optical Society of America B, Vol. 4, No. 6, 1987, pp. 1030-1034. doi:10.1364/JOSAB.4.001030

[15] S. V. Gapoinenko, V. P. Gribkovskii, L. G. Zimin, et al., "Nonlinear Phenomena of Acridine Orange in Inorganic Glass at Nanosecond Scale," Optical Materials, Vol. 104, No. 12, 1993, pp. 53-58.

[16] H. Zhao, W. Zhou, D. Zhu and J. Wu, "Synthesis and Characterization of Low Melting Scintillating Glass Doped with Organic Activator," Nuclear Instruments and Methods in Physics Research A, Vol. 448, No. 3, 2000, pp. 39-42. doi:10.1016/S0168-9002(00)00286-2

[17] X. Wang, Y. Ding, Z. L. Wang and C. G. Hu, "Temperature Driven In-Situ Phase Transformation of PbWO4 Na- nobelts," Journal of Applied Physics, Vol. 109, No. 12 2011, Article ID: 124309. doi:10.1063/1.3601500

[18] J. Geng, D. J. Lu, J.-J. Zhu and H.-Y. Chen, “Antimony (III)-Doped PbWO4 Crystals with Enhanced Photoluminescence via a Shape-Controlled Sonochemical Route," The Journal of Physical Chemistry B, Vol. 110, No. 28, 2006, pp. 13777-13785. doi:10.1021/jp057562v

[19] A. O. M. Stoppani, E. H. Ramos, I. Widuczynski, A. Bennun and E. M. De Pahn, "The Effect of 2,4-Dinitrophenol on the Oxidation of Endogenous and Exogenous Substrates by the Yeast Saccharomyces cerevisiae," In: C. M. Fried, et al., Eds., Use of Radioisotopes in Animal Biology and the Medical Sciences, Vol. 1, Academic Press, London, 1962, pp. 241-252. 